\title{
A new occurrence of Dakotasuchus kingi from the Late Cretaceous of Utah, USA, and the diagnostic utility of postcranial characters in Crocodyliformes
}

Joseph A. Frederickson, Joshua E. Cohen, Tyler C. Hunt, and Richard L. Cifelli

Acta Palaeontologica Polonica 62 (2), 2017: 279-286 doi:https://doi.org/10.4202/app.00338.2016

Cenomanian mesoeucrocodylians from North America are known primarily from isolated teeth and scutes; any associated remains of this age are noteworthy and represent welcome additions to knowledge. Herein, we describe postcranial elements belonging to a single individual goniopholidid from the Mussentuchit Member of the Cedar Mountain Formation. We argue that this individual represents only the second fossil referable to Dakotasuchus kingi, based on overlapping elements, such as the coracoid, dorsal vertebrae, and scutes, which are strikingly similar to their counterparts in the holotype. The coracoid, in particular, is readily distinguished from those belonging to other closely-related crocodilian taxa; enough so to warrant detailed comparisons in the absence of diagnostic cranial material. The new $D$. kingi specimen is nearly $20 \%$ larger than the holotype, with body length and mass estimates comparable to modern American alligators (Alligator mississippiensis), making it one of the largest aquatic predators in the Mussentuchit ecosystem.

Key words: Crocodylomorpha, Goniopholididae, Dakotasuchus, Cretaceous, Cenomanian, Utah, Mussentuchit.

Joseph Frederickson [joseph.a.frederickson-1@ou.edu], Joshua E. Cohen [jecohen@ou.edu ], Tyler C. Hunt [tyler.c.hunt-1@ou.edu], and Richard L. Cifelli [lㅣ@ou.edu], Sam Noble Museum, 2401 Chautauqua Avenue, Norman, Oklahoma, 73072 USA; Department of Biology, University of Oklahoma, Norman, Oklahoma, 73019 USA.

This is an open-access article distributed under the terms of the Creative Commons Attribution License (for details please see creativecommons.org), which permits unrestricted use, distribution, and reproduction in any medium, provided the original author and source are credited. 
Far's Full text (268.4 kB) ।

Foris Supplementary file $(70.4 \mathrm{kB})$ 